\title{
Stress and communication across job levels after an acquisition
}

\author{
T. Lotz and F. Donald* \\ School of Human and Community Development, University of the Witwatersrand, \\ Private Bag 3, Wits 2050, Republic of South Africa \\ donaldf@umthombo.wits.ac.za
}

Received September 2004

\begin{abstract}
Mergers and acquisitions are frequently implemented as a strategy for organizational change, despite a fifty-fifty chance of success. One of the frequently cited reasons for the lack of success is that employee reactions receive inadequate attention. Using a sense-making framework, this research investigated the perceptions of employees at different organizational levels of the stressors that they experienced during an acquisition and their satisfaction with the organizational communication that occurred during the process. A quantitative, non-experimental, cross-sectional design was used. The sample consisted of 102 employees from a recently acquired organization, all of whom attended the same communication 'road show' regarding the acquisition. Results indicated that there were no differences between managers, supervisors and lower-level employees in the quantity or type of stress and satisfaction with communication. Communication satisfaction had an inverse relationship with sources of stress. The results are discussed in terms of power, sense-making and shifting boundaries.
\end{abstract}

*To whom all correspondence should be addressed.

\section{Introduction}

Mergers and acquisitions are frequently implemented as a strategy for organizational change. However, they only have a fifty-fifty chance of being successful despite the favourable strategic, financial and operational assessments that are made prior to the mergers and acquisitions taking place (Covin, Sightler, Kolenko \& Tudor, 1996; Hamel \& Valikangas, 2003; Newman \& Krzystofiak, 1993). While much attention has been paid to the financial aspects of acquisition and merger processes, there has been very little research into the reactions of employees (Freid, Tiegs, Naughton \& Ashforth, 1996; Nalbantien, Guzzo, Kieffer \& Doherty, 2005; Schweiger \& Denisi, 1991) or the stress that they experience during the process (Cartwright \& Cooper, 1993). This oversight exists despite the fact that employee problems have been blamed as being responsible for a third to one half of all merger failures (Cartwright \& Cooper, 1993).

These challenges suggest the need for more sophisticated management of organizations in relation to their human aspects. Communication is one of the strategies that organizations use to manage perceptions of and reactions to mergers and acquisitions (Barrett, 2002). This research investigates the relationship between employee satisfaction with the organizational communication that occurred during an acquisition and their experiences of stress. It focuses on employees from a company that was acquired by another organization. However, the review of existing research below deals with mergers and acquisitions together as reflected in the existing literature. Areas covered in the literature review below include the process that employees adopt to make sense of organizational change, the relevance of job level in the sense-making process, stress in the merger and acquisition context and communication as a strategy for managing organizational change.

While many studies elaborate on the concrete and observable behaviours and actions connected with various organizational changes, few attempt to identify and understand the interpretations and cognitions associated with them (Perrewe \& Zellars, 1999). Consequently, the overarching perspective guiding the formulation of this study is that organizations can be understood as complex sets of multiple, often conflicting, interpretations and social constructions. Such an understanding suggests that an organizational change has many different interpretations. The way in which people make sense of the change varies from person to person and is influenced by particular circumstances (Taylor, 1999).

Sense-making refers to the process whereby organizational members translate an organizational event and construct a meaningful explanation for it. Through this sense-making process, employees develop a shared understanding that helps shape future actions (Thomas, Clark \& Gioia, 1993). The sense-making process is not simply about discovering the meaning of the new reality that follows from an organizational change; sense-making also creates the reality that will exist. The seven properties of sense-making are that it is: grounded in identity construction; retrospective; enactive of sensible environments, social, ongoing; focused on extracted cues, and based on plausibility (Weick, 1995). Because sense-making is grounded in identity construction and based on plausibility, individual differences are expected. As it is enactive of sensible environments and focused on extracted cues, it is expected that individuals in 
different environments make sense of things differently. Identity construction, plausibility, and a particular set of extracted cues are also tied to the characteristics of a particular job and thus people with different jobs will make sense differently (Greenberg, 1995). In other words, different environments and the characteristics of particular jobs create varying perceptions of organizational change.

While employees in different jobs may interpret organizational change differently, it is also possible that employees at different job levels occupy different organizational environments. Job level refers to an individual's position in the vertical hierarchy of the organization and ranges from non-supervisory workers at the lower end of the scale to the chief executive at the upper extreme (Johns \& Saks, 2005). Employees in different jobs and at different organizational levels are likely to experience varying levels of power, autonomy and decision making discretion in their jobs (Greenberg, 1995) with senior organizational members experiencing more of these attributes.

It is possible that employees at different organizational levels interpret and react to changes, such as acquisitions, in different ways (Greenberg, 1995). Further, the reactions of key identity and organizational groups should be considered when managing an acquisition (Covin et al., 1996; Freid et al., 1996; Greenwood, 1996). Job level is one such way of grouping employees and may influence post-acquisition attitudes. Due to the nature of organizational hierarchy, different levels tend to have different understandings, perspectives and thus reactions to occurrences in the organization (Sherer, 1998; Fairfield-Sonn, Ogilvie \& DelVecchio, 2002). These differences may also apply to mergers and acquisitions. Employees with characteristics associated with greater job mobility (for example, higher levels of education, more years until retirement, and more work experience) tend to hold more favourable attitudes towards mergers (Covin et al., 1996). However, it is possible that the strategies used by the organization to manage perceptions and reactions may influence this finding.

Job level tends to form a boundary between groups of employees. The term 'boundary' is used to describe a rule about the relatedness between things (Cross, Yan \& Reis Louis, 2000). The boundary is an essential element of individual, group and organizational identity. It provides not only a sense of being an entity, but also contains the sense-making (or social information processing) processes that continually shape and redefine the individual, group and organization. Boundaries and their related group cohesiveness imply a framework of meaning and attachment that provide a coherent identity and therefore assist in defining how groups differ from each other (Vince \& Broussine, 1996). While all employees, regardless of job level, may be concerned about their job security during a merger or acquisition, employees at different hierarchical levels may have varying interpretations of mergers and acquisitions due to their differing degrees of power prior to the merger or acquisition.
During mergers and acquisitions, issues relating to power typically come to the fore (Isabella, 1990). This could possibly make hierarchical differences especially pertinent at such times. The power balance is likely to change, especially for more senior employees who stand to lose a greater degree of power and influence. This is because acquisitions tend to have clear winners and losers - power is not negotiable and is surrendered to the new parent company on completion of the deal (Appelbaum, Gandell, Yortis, Proper \& Jobin, 2000; Cartwright \& Cooper, 1990). Consequently, acquired firms tend to perceive themselves as having diminished power because of the greater control of the acquiring firm over critical economic and information resources (Covin et al., 1996).

Mergers and acquisitions are highly emotive and destabilizing change events. Marks (1987) suggested that they differ from other major organizational change in three respects: the rate of change, scale of change and the critical mass of the unknown that they represent. They can create a high degree of stress and uncertainty and can lead to lowered morale, job dissatisfaction, unproductive behaviour, acts of sabotage, increased staff turnover, and higher absenteeism rates. In addition to organizational performance being affected, there is likely to be a negative impact on the physical and mental wellbeing of employees (Appelbaum, et al., 2000; Cartwright \& Cooper, 1990; Hallabrin, 2003; Sirower \& Lipin, 2003).

A transactional model of stress is adopted for this study. Stress is seen as a process of continual transaction between external demands and constraints, external supplies and supports, personal resources and internal needs and values, in which the individual strives to maintain a balance (Daniels \& Guppy, 1994). Moreover, transactional theories recognize that different stimuli have different characteristics and each individual has different levels of perceived ability to cope with these stimuli, different perceptions of the demands of these stimuli and of the importance of meeting those demands (Beehr \& Bhagat, 1985). Therefore transactional models place the phenomenon of stress firmly within the cognition of the individual and indicate that social and organizational variables should be studied together in order to determine the relationship between stressors and the associated outcomes (Daniels \& Guppy, 1994).

Applied to the merger and acquisition context, merger stress may be seen as an imbalance between the requirement to make an adaptive response to the change and the repertoire of the individual. The change involves the merger or acquisition events as seen and experienced by the individual. Major strategic changes generate ambiguity about potential terminations, transfers, and the need to survive in a new and relatively unknown situation. Transitions may also generate worries about reward contingencies. There is likely to be uncertainty regarding procedures and norms as well as a lack of guidelines for acting appropriately in a changing context (Fairfield et al., 2002). The greater the uncertainty surrounding the merger, the greater the perceived discrepancy between the pressure of the acquisition and the individual's response capacity. In addition, the higher the appraised cost of responding, the more stress is likely to be perceived (Abrahamson, 2004; Appelbaum et al., 2000). 
Responding to stress involves perceptual interpretive behaviour and physiological adjustments. How individuals interpret the stressors is crucial to their responses to them. This is determined by the degree to which individuals perceive events as threatening, harmful or challenging. Demands that challenge or surpass an individual's ability to adapt are likely to result in an interpretation of the demands as being stressful (Appelbaum, Gandell, Shapiro, Belisle \& Hoeven, 2000; Perrewe \& Zellars, 1999 ). Stress arises more from employees' perceptions of changes that might result than the effects of the changes themselves (Mann, 1996).

Communication is one of the methods used to manage employees' reactions to acquisitions and can set the climate for uncertainty or assurance (Abrahamson, 2004; FairfieldSonn et al., 2002). Effective communication can assist in managing uncertainty during an acquisition and is likely to assist in fostering a sense of fairness, procedural and interactional justice. In turn, these perceptions are likely to enhance acceptance of the change (Cobb, Wooten \& Folger, 1995). Most researchers believe intuitively that a positively perceived communication environment contributes to organizational effectiveness (Pincus, 1986; Szpekman, 2004). Research suggests that employees' perceptions of top management and their communication activities may influence employees' job satisfaction and performance (Covin et al., 1996; Zhu, May \& Rosenfeld, 2004). Therefore the construct of communication satisfaction is used in this study. The construct is based on factor analytic studies of different forms of communication (Downs \& Hazen, 1977). It is described as a summing up of an individual's satisfaction with communication, based on his / her perceptions or interpretations (Pincus, 1986; Redding, 1978). Thus it ties in with the social information processing approach.

It has long been established that people turn to communication in situations where uncertainty is high and physical evidence is not available (Festinger, 1954). They tend to use communication to develop stable, socially derived interpretations of events and their meanings. This could apply to mergers and acquisitions where uncertainty is high. Although communication plays an important role in times of uncertainty, it can also be more difficult to communicate effectively during times of threat and stress. Under stressful circumstances, individuals become less able to discriminate between various items of information and often ignore peripheral information relevant to the problem at hand (Shaw \& Barrett-Power, 1997). Further, during an acquisition, providing information is or may be perceived by management to be difficult, undesirable, or simply not possible. During periods of organizational stress, employees desire more information, but this is usually at a time when managers cannot meet this need (Richardson \& Denton, 1996). Fearing that they may mislead or that the information may be erroneous, managers often fall silent, and therefore do not meet employees' need for information.

The present study examines the role of communication satisfaction in moderating perceived stress during an acquisition. Based on sense making theory, this is examined across different job levels. Different appraisals of stressors and interpretations of the acquisition and communications processes at different job levels would presumably provide indicators that different communications are required at the various levels in order to assist in managing the acquisition process effectively.

The hypotheses applied specifically to acquisitions and were that:

1. Employees at different job levels experience different perceived sources of stress.

2. Employees at different job levels experience different levels of communication satisfaction.

3. There is a relationship between perceived sources of stress and communication satisfaction.

\section{Methodology}

A non-experimental, cross-sectional, correlational research design was used.

\section{Participants}

The research was conducted in an insurance company in Gauteng. The company had been acquired due to poor performance in difficult operating conditions. Various benefits and synergies from the acquisition were anticipated for both the acquired and the acquiring organizations.

Questionnaires were distributed to every employee at all levels in the acquired organization (200) and 105 were returned. One hundred and two questionnaires were suitable for analysis, indicating a response rate of 51 percent. The sample consisted of 102 employees, all of whom participated voluntarily. The organization's job grading system was used in order to determine job level, resulting in four job levels. The sample consisted of top management (2\%), middle management (23\%), supervisors (19\%) and employees (56\%). However, since only two top managers responded to the questionnaire, this level was excluded in order to maintain confidentiality and to ensure comparable group sizes for analysis. Participants' ages ranged from 19 to 59 years, with a mean of 37 years. The minimum length of service was 0,6 years and the maximum was 38 years. Approximately two-thirds of the sample was female. Twothirds of the sample had a matric, 16 percent had a postmatric qualification and 13 percent had not reached matric level.

\section{Measuring instruments}

To evaluate sources of stress, the 'sources of pressure' questionnaire of the Occupational Stress Indicator (Cooper et al., 1978) was used. Only 21 of the 61 items from the sources of pressure questionnaire were used, based on their relevance to the acquisition. These items were the same as those selected by Cartwright and Cooper (1993) and are considered to be highly pertinent to merger and acquisition situations (Cartwright \& Cooper, 1993). The items were obtained from 5 of the 6 sub-scales including factors intrinsic to the job (alpha $=0,64$ ); the managerial role (alpha 
$=0,62)$; relationships with others (alpha $=0,63$ ); career and achievement (alpha $=0,66$ ); and organizational structure and climate (alpha $=0,64)$ (Cartwright, Cooper \& Barron, 1996). For the current study, a Cronbach's alpha of 0,92 was obtained for the combined sub-scales. The reliability of the Occupational Stress Indicator has been established in a number of studies and Cronbach's alpha ranged from .76 to 0,91 (Cooper et al., 1988). Predictive and concurrent validity have also been established (Cartwright \& Cooper, 1990). The scale has been used previously in South Africa for stress-related research (Reingold, 1999). Items were scored by means of an anchored six-point Likert type scale.

Communication satisfaction was measured using Downs and Hazen's (1977) Communication Satisfaction Questionnaire and the additional dimension (top management communication) developed by Pincus (1986). The scale sums up an individual's satisfaction with information flow and relationship variables (Pincus, 1986) and treats communication satisfaction as a multidimensional construct. The scale was divided into eight distinct dimensions, each with five items, yielding a total of 40 items. The dimensions were communication climate, supervisor communication, media quality, organizational integration, personal feedback, organizational perspective, subordinate communication, and top management communication. The original dimension of horizontal communication was omitted as this measures perceptions of grapevine communication and does not reflect formal communication associated with the merger.

The communication satisfaction scale was developed in three stages. First, a questionnaire was developed based on literature, other research instruments, three pilot studies in the form of marker variables, and a collection of critical incidents. This was administered and factor-analyzed. Second, the existing questionnaire was refined, administered to four different organizations and again factor-analyzed. Lastly, the each factor was correlated with job satisfaction to explore which factors were related to job satisfaction (Downs \& Hazen, 1977).

A five-point Likert type scale ranging from very dissatisfied to very satisfied was used. The communication satisfaction scale has been found to be internally consistent with reliabilities around .95 and compares favourably with reliability scores in other studies (Crino \& White, 1981; Downs \& Hazen, 1977). Sub-scale reliability estimates (Cronbach's alpha) of the communication satisfaction instrument have been found to range from .72 to .96 (Downs, 1991; Potvin, 1992). For the current study, a Cronbach's alpha of 0,96 was obtained for the combined dimensions. In addition to the scale, participants were asked to assess their overall satisfaction with communication. Thus both multidimensional and global measures of communication satisfaction were gathered. Participants were asked to answer the questionnaires in the context of the acquisition.

\section{Procedure}

Data was collected two weeks after the Financial Services Regulatory Board had approved the acquisition. Prior to data collection during the two-week period, the acquiring organization conducted a communication 'road show' to inform employees about the acquisition. All employees had attended the 'road show' before completing the questionnaire. In addition, employees who were going to be retrenched were identified and informed during this time period. Employees who were being retrenched may have experienced a substantial decrease in organizational commitment. Therefore it is possible that few of the employees who were being retrenched would have completed the questionnaires, thus biasing the sample and results and reducing the response rate (51 percent). As participation was voluntary, anonymous and confidential, there was no way of ascertaining whether this occurred. However, this may limit the generalizability from the response group to the organization as a whole.

\section{Results}

Prior to detailing results for the hypotheses, general trends in the data based on descriptive statistics for the dependent variables are provided in Table 1.

Table 1: Descriptive statistics for sources of stress and communication satisfaction

\begin{tabular}{l|l|l|l|l|l|l}
\hline & N & $\begin{array}{c}\text { No. } \\
\text { of } \\
\text { items }\end{array}$ & Min. & Max & Mean & $\begin{array}{c}\text { Std. } \\
\text { Dev }\end{array}$ \\
\hline Sources of stress & 102 & 21 & 43 & 120 & 86,39 & 17,48 \\
\hline $\begin{array}{l}\text { Communication } \\
\text { satisfaction }\end{array}$ & 102 & 40 & 49 & 160 & 118,78 & 25,82 \\
\hline
\end{tabular}

High levels of stress were present in the sample, as evidenced by the relatively high mean score relative to the minimum and maximum scores, and the small standard deviation. For communication satisfaction, the mean score (118.78) is closer to the maximum than the minimum score, indicating some satisfaction with the communication regarding the acquisition despite the large range of scores.

\section{Hypotheses 1 and 2}

In order to test whether different job levels experienced different sources of stress and different levels of satisfaction with communication, MANOVAs were conducted. Prior to this, it was necessary to test the assumptions underlying MANOVA, namely that there must be equality in the covariance matrices of the dependent measures for each group. The requirement of equivalence is a strict test because instead of equal variances for a single variable in ANOVA, the MANOVA test examines all elements of the covariance matrix of the dependent variables (Hair, Andersen, Tatham, \& Black, 1998). The Box test is a statistical test for the equality of the variance / covariance matrices of the dependent variables across the groups. The Box test provided a significance level of $\mathrm{p}=0,05$ (alpha $=$ 0,05 ), indicating that the observed covariance matrices were equal across job levels. Thus the assumptions of normality and independence were satisfied prior to analysis.

The MANOVA model tests for differences in group means, providing a single overall test of group differences at a specified alpha level and forming and testing the linear 
combinations of the dependent variables that provide the strongest evidence of overall group differences (Hair et al., 1998). The indications are that both variables (sources of stress and communication satisfaction) do not differ across the three different job levels $(p=0,62$, alpha $=0,05 ; \mathrm{p}=$ 0,49 , alpha $=0,05$ respectively) (Table 2 ).

Table 2: MANOVA for the effects of job level on sources of stress and communication satisfaction

\begin{tabular}{l|l|l|l|l|l}
\hline \multicolumn{1}{c|}{ Source DV } & \multicolumn{1}{c|}{$\begin{array}{c}\text { Sum of } \\
\text { squares }\end{array}$} & df & $\begin{array}{c}\text { Mean } \\
\text { square }\end{array}$ & F & Sig. \\
\hline Job level sress & 300,84 & 2 & 150,42 & 0,48 & 0,62 \\
Communication & 981,62 & 2 & 490,81 & 0,73 & 0,49 \\
\hline
\end{tabular}

The result is supported by an analysis of the means (Table 3) where there are no significant differences across the various job levels. Consequently, job level had no effect on the sources of stress experienced, both jointly (Table 2) and independently (Table 3).

Table 3. Estimated marginal means across job levels

\begin{tabular}{lr|c|c}
\hline Dependent variable & Mean & Std. Error \\
\hline Sources of stress & Job Level & & \\
& Manager & 85,74 & 3,53 \\
& Supervisor & 90,03 & 4,05 \\
Employee & 85,56 & 2,34 \\
\hline Communication satisfaction & & 5,20 \\
& Manager & 123,83 & 8,97 \\
& Supervisor & 114,74 & 3,45 \\
\hline
\end{tabular}

\section{Hypothesis 3.}

Communication satisfaction was found to be significantly negatively correlated with sources of stress based on the Pearson product moment coefficient $(r=-0,33, p<0,01)$.

\section{Discussion}

The results of this study indicated that there were no differences between managers, supervisors and lower-level employees in the quantity or type of stress experienced and satisfaction with communication. This finding runs counter to previous research which indicates that employees at different levels of the organizational hierarchy tend perceive and interpret organizational occurrences differently (Fairfield-Sonn et al., 2002; Sherer, 1998). The lack of significant differences can be interpreted in several ways and is important since it appears to point to the uniqueness of the acquisition situation.

It is argued that owing to the transformational nature of the change involved in an acquisition and the imbalance of power inherent in the acquirer-acquired relationship, group composition shifts from being defined by hierarchical level to acquired and acquirer groups. Thus differences in perceptions are likely to occur between organizations rather than within the acquired organization as may have been the case prior to the acquisition.
The communication 'road show' that took place could have affected the results by influencing perceptions towards a common norm. Thus, the way in which the acquisition was managed and communicated in this particular case could have assisted in creating a perception common to employees at all levels. Further, the management of the acquired organization could have contributed to the creation of shared perceptions through any communications that they had held with employees. Part of a manager's role is to interpret ambiguous events and to provide meaning and direction for organizational members (Johns \& Saks, 2005). This function would apply to the acquiring organization and possibly to managers within the acquired firm. The implication of being able to create a shared understanding is that leaders can use their positions to direct organizational members toward a desired mode of understanding and action. When this occurs, organizational members will then construct an interpretation of the change that mirrors the leaders' framed interpretation (Greenberg, 1995). Вy managing sense-making, leaders may be able to maintain considerably more control over the outcomes of a change.

Although the road show and other communications probably played a role in creating common perceptions and understandings, other factors may have been instrumental in creating similar levels of satisfaction with the communications that took place. In merger and acquisition situations, actions by the acquirer tend to be read as communication even when they are not intended as such, and this has a negative effect on the acquired organization (Mosher \& Pollack, 1995). Employees in acquired organizations tend to be suspicious of the new owners and constantly scan their communication for signs of being deceived.

Owing to the nature of the power differential in acquisitions, uncertainty and insecurity, lower-level employees and executives alike generally wonder how the combination will affect them (Robino \& DeMeuse, 1985). Therefore the sources of stress are in many instances the same for employees at all levels. The focus shifts from position in the organizational hierarchy to the acquirer and during this process, it is possible that the boundaries between employees in the acquired firm also change. Thus the notion of shifting boundaries provides one possible explanation of the results.

It is argued that during the acquisition in the current study, the boundaries shifted from those based on hierarchical level, to groups and identities based on membership of the acquired or acquiring organizations. Thus employees in the acquired firm would become more cohesive as a group and would tend to hold more similar perceptions of the acquisition. It is possible that the acquisition in this study brought management and employees closer together and that the common 'enemy' then became the acquirer against whom all could rally in a unified manner. This interpretation is supported by previous research where acquisitions increased intra-organizational cohesiveness and heightened resistance to change (Appelbaum, Gandell, Shapiro, Belisle \& Hoeven, 2000; Newman \& Krzystofiak, 1993; Zhu et al., 2004). 
In addition, more cohesive groups experience less variance in their attitudes (Johns \& Saks, 2005). During an acquisition, the traditional boundaries between groups of employees, such as job levels, may become less important or even irrelevant as the boundaries shift to include the entire acquired organization. This may be related to the inherently conflictual nature of the power differentials during an acquisition.

Stress levels were high and did not differ significantly across job levels. Further, in this study, sources of stress correlated negatively with communication satisfaction, suggesting the need to manage stress as part of the communication strategy during mergers and acquisitions. Merger stress is triggered largely by the expectation of change and fears for future survival, rather than the actual change itself (Cartwright \& Cooper, 1993) and as a result can possibly be managed to a certain extent.

Communication during an acquisition is a complex process. Despite the difficulties involved and the lack of answers to unresolved issues in the acquisition process, it is recommended that a communication strategy receive priority during mergers and acquisitions. Communication should focus on areas of particular concern to employees during mergers and acquisitions, such as layoffs and changes to pensions, work rules and compensation (Schweiger \& Denisi, 1991). It should be aimed at making employees' expectations of the merger or acquisition more realistic so that expectations have a greater chance of being fulfilled (Fairfield-Sonn et al., 2002). The strategy should include the communication of information that is known, statements regarding issues that are not yet known, time parameters regarding decisions, offers to answer questions, explanations as to why some questions cannot be answered and attempts to ensure that employees are not intentionally deceived. Further, communication should be geared to prevent boundaries developing between the acquired and acquiring employees that are likely to undermine the effectiveness of the new organization.

It should be borne in mind that stress often distorts communication at a time when the demand for information is at its highest, and when openness of communication is not characteristic (Schweiger \& Ivancevich, 1985). Employees are likely to attend to the most pessimistic information, regardless of the validity of the source. Thus formal and informal channels of communication need to be used in order to manage rumours and negative perceptions. The complex interplay between stress and communication during times of rapid organizational change is supported by the significant relationship between these two variables in this study.

Organizational researchers have often assumed that a priori structural categorizations such as level in a hierarchy, and in this study job level, are an adequate basis for aggregating perceptions of organizational processes (Meyer, 1994). The theory, methods and results here suggest that there may be other useful approaches to aggregating responses (for example, acquired and acquirer) which would not risk masking important sources of variation in those responses. The findings of this study suggest that, contrary to Napier et al.'s (1989 cited in Covin et al., 1996) suggestion, merger implementation strategy and type of communication does not need to vary by employee group, depending on employee needs and concerns. Rather, generic intervention programs may be appropriate for the acquired form, since owing to the enormous impact of the acquisition, employee hierarchy appears to become obsolete and in the current study, the entire acquired firm experienced similar perceptions and attitudes.

Due to the high stress levels in the organization and the relationship between sources of stress and communication satisfaction, it becomes essential for managers and practitioners to manage the stress associated with acquisitions. More specifically, recognizing and addressing the issue of merger stress is one way in which organizations could reduce the adverse individual and organizational outcomes associated with stress. Merged employees are likely to find the uncertainty of the merger situation as stressful, and perhaps even more stressful, than any actual changes (Cartwright \& Cooper, 1993). According to the relationship between sources of stress and communication satisfaction found in this study, uncertainty may be reduced by the introduction of frequent and consistent communication of merger-related information. In fact, as stress appears to arise more from the perceptions which employees have as to the likely changes which may result rather than the effects of the changes themselves (Schweiger \& Ivancevich, 1985), the presentation of realistic merger or acquisition previews, similar to job previews, are likely to be useful. Realistic information provides employees with a basis for action other than rumours and should assist in reducing stress and uncertainty. Further, the communication process symbolizes the organization's concern for its employees and tends to create increased commitment (Schweiger \& Denisi, 1991). Because all the communication sub-scales were equally significant in this study, all eight aspects, including communication climate, supervisor communication, organizational integration, subordinate communication, personal feedback, organizational perspective, media quality and upper management communication, should be part of the communication process or intervention.

As this research was based on one acquisition only, there is a need to replicate it in other organizations to ascertain whether similar results would be found. In addition, a longitudinal study using triangulation of qualitative and quantitative methods would be useful as the perceptions and interpretations of organizational members could be explored in more depth and tracked over time. The specific inclusion of employees who leave the organization and those who remain after a merger would also be useful, as would studies of friendly versus hostile mergers. 


\section{References}

Abrahamson, E. 2004. Change without pain: how managers can overcome initiative overload, organisational chaos, and employee burnout. Boston: Harvard Business School Press.

Appelbaum, S. H., Gandell, J., Yortis, H., Proper, S. \& Jobin, F. 2000. 'Anatomy of a merger: Behavior of organizational factors and processes throughout the preduring- post-stages. Part 1', Management Decision, 38(9):649-661.

Appelbaum, S. H., Gandell, J.,Shapiro, B. T., Belisle, P. \& Hoeven, E. 2000. 'Anatomy of a merger: Behavior of organizational factors and processes throughout the preduring- post-stages. Part 2', Management Decision, 38(10): 674-684.

Barrett, D.J. 2002. 'Change communication: Using strategic employee communication to facilitate major change', Corporate Communication, 7(4): 219-231.

Baum, A., Singer, J.E. \& Baum, C.S. 1981. 'Stress and the environment’, Journal of Social Issues, 37(1): 4-33.

Beehr, T.A. \& Bhagat, R.S. (Eds.). 1985. Human stress and cognition in organizations: An integrated perspective. New York: Wiley.

Cartwright, S. \& Cooper, C.L. 1990. 'The impact of mergers and acquisitions on people at work: existing research issues', British Journal of Management, 1(2): 6576.

Cartwright, S. \& Cooper, C.L. 1993. 'The psychological impact of merger and acquisition on the individual: a study of building society managers', Human Relations, 46(3): 327-347.

Cartwright, S., Cooper, C.L. \& Barron, A. 1996. 'The company car driver: Occupational stress as a predictor of motor vehicle accident involvement', Human Relations, 49(2): 195-206.

Cobb, A.T., Wooten, K.C. \& Folger, R. 1995. 'Justice in the making: Towards understanding the theory and practice of justice in organizational change and development', Research in Organizational Change and Development, 8:243-295.

Cooper, C.L. \& Marshall, J. 1978. Understanding executive stress. London: Macmillan.

Cooper, C.L. \& Payne, R. 1988. Causes, coping and consequences of stress at work. Chichester: John Wiley \& Sons.

Covin, T.J., Sightler, K.W., Kolenko, T.A. \& Tudor, R.K. 1996. 'An investigation of post-acquisition satisfaction with the merger', Journal of Applied Behavioural Science, 32(2): 125-142.
Crino, M. D. \& White, M. C. 1981. 'Satisfaction in communication: An examination of the Downs-Hazen measure', Psychological Reports, 49: 831-838.

Cross, R.L., Yan, A. \& Reis Louis, M. 2000. 'Boundary activities in "boundaryless" organizations: A case study of transformation to a team-based structure', Human Relations, 53(6), 841-868.

Daniels, K. \& Guppy, A. 1994. 'Occupational stress, social support, job control, and psychological well being', Human Relations, 47(12):1523-1544.

Downs, A. 1991. 'The relationship between communication and organizational commitment in two Australian organizations'. Unpublished Master's thesis, University of Kansas, Lawrence.

Downs, C.W. \& Hazen, M.D. 1977. 'A factor analytic study of communication satisfaction', The Journal of Business Communication, 17(3): 63-73.

Fairfield-Sonn, J. W., Ogilvie, J. R. \& DelVecchio, G. A. 2002. 'Mergers, acquisitions and long-term employee attitudes', The Journal of Business and Economic Studies, 8(2): 1-16.

Festinger, L. 1954. 'A theory of social comparison processes', Human Relations, 7:114-140.

Freid, Y., Tiegs, R.B., Naughton, T.J. \& Ashforth, B.E. 1996. 'Managers' reactions to a corporate acquisition: A test of an integrative model', Journal of Organizational Behaviour, 17:401-427.

Greenberg, D.N. 1995. 'Blue versus grey: A metaphor constraining sensemaking around a restructuring', Group and Organization Management, 20(2): 183-209.

Greenwood, R. 1996. 'Managers' reactions to a corporate acquisition: Comment on Freid, Tiegs, Naughton and Ashforth', Journal of Organizational Behaviour, 17: 429430.

Hallabrin, R. 2003. 'Yours, mine and ours: The public relations of mergers and acquisitions', Franchising World, 35(2): 49-50.

Hair, J.F., Andersen, R.E., Tatham, R.L. \& Black, W.C. 1998. Multivariate data analysis. ( $5^{\text {th }}$ Edition). New Jersey: Prentice Hall Inc.

Hamel, G. \& Valikangas, L. 2003. 'The quest for resilience', Harvard Business Review, September :1-13.

Isabella, L.A. 1990. 'Evolving interpretations as change unfolds: How managers construe key organisational events', Academy of Management Journal, 33(1):7-41.

Johns, G. \& Saks, A. M. 2005. Organizational behaviour: Understanding and managing life at work. ( $6^{\text {th }}$ Edition). Toronto: Pearson Education. 
Klein, S.M. 1996. 'A management communication strategy', Journal of Organizational Change Management, 9(2):32-46.

Marks, M.L. 1987. 'The merger syndrome: the human side of combination', Journal of Buyouts and Acquisitions, (Jan/Feb):18-23.

Mann, S. E. 1996. 'Employee stress an important cost in mergers’, Business Insurance, 30(48): 24.

Meyer, G. W. 1994. 'Social information processing and social networks: a test of social influence mechanisms', Human Relations, 47(9), 1013-1047.

Mosher, D. J. \& Pollack, D. 1995. 'Managing the human dimensions of mergers and acquisitions in the banking industry', The Bankers Magazine, 178(5):55-61.

Nalbantien, H. R., Guzzo, R. A., Kieffer, D. \& Doherty, J. 2005. 'Making acquisitions work', Journal of Organizational Excellence, 24(2): 45-52.

Newman, J. M. \& Kryzstofiak, F. J. 1993. 'Changes in employee attitudes after an acquisition', Group \& Organization Management, 18(4): 390-411.

Perrewe, P. L. \& Zellars, K. L. 1999. 'An examination of attributions and emotions in the transactional approach to the organizational stress process', Journal of Organizational Behavior, 20(5): 739-752.

Pincus, J.D. 1986. 'Communication satisfaction, job satisfaction and performance', Human Communication Research, 12(3):395-419.

Potvin, T. C. 1992. 'Employee organizational commitment: An examination of its relationship to communication satisfaction and an evaluation of questionnaires designed to measure the construct'. (Doctoral dissertation, University of Kansas, 1991). Dissertation Abstracts International, 52: 4147A.

Redding, W. C. 1978. Communication within the organization. New York: Industrial Communication Council.

Reingold, U. 1999. 'The efficacy of workplace stress management interventions in reducing workplace stress'. Unpublished Masters Dissertation, University of the Witwatersrand, Johannesburg.

Richardson, P. \& Denton, D.K. 1996. 'Communicating change’, Human Resource Management, 35(2):203-216.

Robino, D. \& DeMeuse, K. 1985. 'Corporate mergers and acquisitions: The impact on HRM', Personnel Management, November: $33-44$.

Schweiger, D.M. \& Denisi, A.S. 1991. 'Communication with employees following a merger: A longitudinal field experiment', Academy of Management Journal, 34(1):110135.
Schweiger, D.M. \& Ivancevich, J.M. 1985. 'Human resources: The forgotten factor in mergers and acquisitions', Personnel Administrator, November: 47-61.

Shaw, J.B. \& Barrett-Power, E. 1997. 'A conceptual framework for assessing organization, work group, and individual effectiveness during and after downsizing', Human Relations, 50(2):109-127.

Sherer, M. 1998. 'Organisational position: Influence on perceived organisational properties', Journal of Sociology and Social Welfare, 25(4): 3-18.

Sirower, M.L. \& Lipin, S. 2003. 'Investor communication: A message of confidence in the deal', Mergers and Acquisitions, 38(10):21.

Szpekman, A. 2004. 'Guiding principles during a merger', Strategic Communication Management, 8(4): 9.

Taylor, S. S. 1999. 'Making sense of revolutionary change: Differences in members' stories', Journal of Change Management, 12(6):524-539.

Thomas, J. B., Clark, S. M. \& Gioia, D. A. 1993. 'Strategic sensemaking and orgnisational performance: Linkages among scanning, interpretation, actions and outcomes', Academy of Management Journal, 36:239-270.

Vince, R. \& Broussine, M. 1996. 'Paradox, defence and attachment: Accessing and working with emotions underlying organizational change', Organization Studies, 17(1):1-21.

Weick, K.E. 1995. Sensemaking in organisations. Thousand Oaks: Sage.

Zhu, Y., May, S. K. \& Rosenfeld, L. B. 2004. 'Information adequacy and job satisfaction during merger and acquisition', Management Communication Quarterly, 18(2): 241-270. 